\title{
Correction to: Efficiency in PrEP Delivery: Estimating the Annual Costs of Oral PrEP in Zimbabwe
}

\author{
Collin Mangenah ${ }^{1,9} \cdot$ Definate Nhamo $^{2}(-)$. Stephano Gudukeya ${ }^{3} \cdot$ Emily Gwavava $^{2} \cdot$ Chiedza Gavi $^{1}$. \\ Progress Chiwawa $^{1} \cdot$ Sandra Chidawanyika ${ }^{1} \cdot$ Polite Muleya $^{1} \cdot$ Noah Taruberekera $^{3}\left(\right.$ D $\cdot$ Ngonidzashe Madidi $^{3}(0)$

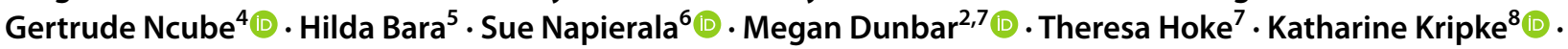 \\ Frances M. Cowan ${ }^{1,9} \cdot$ Kristine Torjesen $^{7}$ (D) Fern Terris-Prestholt ${ }^{10}$ (i)
}

Published online: 5 October 2021

(c) Springer Science+Business Media, LLC, part of Springer Nature 2021

\section{Correction to: AIDS and Behavior https://doi.org/10.1007/s10461-021-03367-w}

The original version of this article unfortunately contained an error in Supplementary, and it has been corrected with this erratum.

Supplementary Information The online version contains supplementary material available at https://doi.org/10.1007/s10461-021-03480-w.

Publisher's Note Springer Nature remains neutral with regard to jurisdictional claims in published maps and institutional affiliations.

The original article can be found online at https://doi.org/10.1007/ s10461-021-03367-w.

Collin Mangenah

Collin@ceshhar.co.zw; Colin.Mangenah@1stmed.ac.uk;

cmangenah1@gmail.com

1 Centre for Sexual Health, HIV/AIDS Research, 4 Bath Road, Belgravia, Harare, Zimbabwe

2 Pangaea Zimbabwe AIDS Trust (PZAT), Harare, Zimbabwe

3 Population Services International Zimbabwe, Harare, Zimbabwe

4 Ministry of Health and Child Care, Harare, Zimbabwe

5 Harare City Health Department, Harare, Zimbabwe

6 RTI International, Durham, NC, USA

7 FHI 360, Durham, NC, USA

8 Avenir Health, Takoma Park, MD, USA

9 International Public Health Department, Liverpool School of Tropical Medicine, Liverpool, UK

10 London School of Hygiene and Tropical Medicine, London, UK 